\title{
Clinical Stage IIA Cutaneous Melanoma AJCC v8
}

National Cancer Institute

\section{Source}

National Cancer Institute. Clinical Stage IIA Cutaneous Melanoma A/CC v8. NCI

Thesaurus. Code C137652.

Stage IIA includes: (T2b, N0, M0); (T 3a, N0, M0). T2b: Tumor measuring more than 1.0 and equal to or less than $2.0 \mathrm{~mm}$ in thickness. Ulceration status: With ulceration. T3a: Tumor measuring more than 2.0 and equal to or less than $4.0 \mathrm{~mm}$ in thickness.

Ulceration status: Without ulceration. N0: No regional lymph node metastasis detected. Presence of in-transit, satellite, and/or microsatellite metastases: No. M0: No evidence of distant metastasis. LDH level is not applicable. (AJCC 8th ed.) 